\title{
The Role of Physical Education in Developing Students' Social and Psychological Qualities of a Personality
}

\author{
Irina Kalina*, Aleksandr Golubev, Rustam Aidarov \\ Kazan Federal University, Naberezhnye Chelny Institute
}

\begin{abstract}
When communicating with the surrounding people each person shows his / her social and psychological personal qualities. The development of these qualities is influenced by a large number of factors. Physical education plays a significant role in this process. The development of social and psychological qualities manifests itself in the presence of one's own beliefs and views on various phenomena and events in society; in the acquired social attitudes and requirements both in relation to himself and to other people; in the ability to make decisions and bear responsibility for them; in the ability to master and carry out various social roles; in the efficiency of interaction with various social groups of people; in willingness for self-education, etc. The article characterizes the process of physical education at a university as one of the spheres of educational activity which promotes social adaptation of students to the conditions of the university, and develops future professionals' socially and professionally significant personal qualities and the ability for efficient activity in the constantly changing conditions of the social environment and social production. The authors emphasize the importance of pedagogical, social and psychological environment in which the process of a personality development is realized.
\end{abstract}

\section{Introduction}

Use University education which including academic, scientific, social, sports and creative activities is the initial stage of professional training and adaptation of future specialists to constantly changing conditions of social environment and public production. Therefore, the modern system of higher education must provide not only the transmission of certain knowledge, but also the development of a specialist possessing a number of socially and professionally significant personal qualities and abilities that determine the professionalism of a graduate $[1,2,3]$. They include an ability to manage new social roles, make quick decisions and take responsibility for them, the skills of effective interaction with colleagues on the basis of generally accepted norms and rules, willingness for lifelong self-education, the awareness of the importance of a healthy lifestyle for a successful self-realization in the society, etc. [4, 5, 6].

One of the most effective factors contributing to the social adaptation of students to training conditions of the university, and developing the ability of a future specialist to quickly adapt in society, is the physical and sports activities conducted by the university during classes of physical education and after them. It creates a favorable environment for effective integration of a freshmen into the new student body, a new educational life much different from the previous, school life (in style, requirements, content, and teaching methods, in the interactions of the individual with the environment) $[7,8]$.

Today sports activities are becoming a part of the daily life of the population, receive mass recognition and development, become popular among young people. Physical exercises are effectively used in the work and rest of people, become real and effective basis for improvement of health, quality of life, and human selfimprovement.

Physical education in general has a fairly wide variety of pedagogical and social effects. A significant number of scientific papers [9, 10 and many others] describe in details the means of physical culture, sport and tourism from the recreational, developmental, and educative perspective. They are represented also in terms of the need of a person for adaptation to new environmental conditions of life, comprehensive preparation for production activities, and performance of biological functions [11]. We should not forget that physical exercise is a sphere of activity, where there is an active adaptation of the individual to the social environment conditions, that is, the social adaptation (for students - an adaptation to the new high school environment). In the course of sports activity the students are involved in public life, develop their experience in social relations and the leadership qualities, hone their organizational skills. Here they expand their circle of contacts and develop a number of positive moral and strong-willed personality traits such as sense of purpose, determination, responsibility, etc.

* Corresponding author: KalinaIrinaGenn@yandex.ru 
Therefore, the activation of mental and creative components of the student's individual at high school should be in parallel with the stimulation of its motor activity.

The objectives of this study included a more detailed definition of the role of physical education in the promotion of social adaptation of students to educational activity in the high school environment. As the features of social adaptation, we chose: the effectiveness of training activities and the proactive participation in public life of an institute, the compliance with the moral and ethical norms of behavior and the discipline, good relations with members of the student body and the ability to perform leader's functions, the responsibility, and the creative approach to the implementation of public orders and the study. According to some authors $[1,2]$, these features reflect the pedagogical essence of social adaptation of students.

\section{Materials and methods}

The research methods were: questionnaire survey, pedagogical observation, analysis of scientific literature, and statistical methods of experimental data processing.

The research was carried out in 2017. An anonymous survey involved 1st-4th-year students of the three faculties of Naberezhnye Chelny Institute of Kazan (Volga) Federal University. The sample (239 people) consisted of students who were regularly attending classes in physical culture. Total 121 boys and 118 girls were interviewed. Distribution of the number of the students by the year of study is also represented in roughly equal proportions.

When drawing up a questionnaire and formulating its questions, we used a statement as a reference that sports activity contributes to social adaptation of students in the following aspects.

At the physiological level, physical and sports activities of students, organized by the university on the basis of the implementation of pedagogical principles and focused on the development of a number of physical properties, including endurance, helps to improve the functional abilities and the energy potential of the organism of sportsmen. Thus, by improving adaptability to physical stress, the physical and mental performance, as well as activation of young people to study is promoted, which in turn affects their performance and the quality of professional training [12]. Adaptability to considerable physical stress contributes also to psychological adaptation of students to educational activity [13].

Educational activity is a part of the social adaptation and socialization of the individual. During the classes in high school the students acquire new skills, particularly in the field of physiology and theory of self-organization of sports activities and acquire the applied skills necessary for their future professional activity, increase social and humanitarian competence, improve the dialectical-materialist worldview. Classes in physical culture, in addition to their main focus (improvement of motor activity of students during the training and development of physical culture of a person, which will provide in post-graduate life the further possibility of effective physical self-improvement), provide also an understanding of the need for a healthy lifestyle.

Physical improvement, in addition to the above, is associated with the development of strong-willed and moral traits, therefore, the reliable management of classes also provides a humanistic education of students. This catalyzes the spiritual maturation of the individual. Those practicing sports are characterized by an earlier independence, discipline, the ability to plan their educational and sports activities, the willingness to set goals and achieve them, to take responsibility for mistakes. Athletes usually practicing sports in teams and groups are characterized by internationalism of views, the adoption of moral norms and social values of people of other faiths and races, a sense of community. This contributes to the unity of the academic staff and the establishment of positive interpersonal relationships there. In subsequent production activities, the similar experience is projected onto the labor collective.

During collective activities, a person feels the support of like-minded sports enthusiasts, which gives it self-confidence. The circle of his/her social contacts increases, communication skills develop. Young people learn new social roles in a team, develop the individualized programmes and style of behavior, at acquiring the same time a multi-faceted set of personality traits and a unique identity.

Active participation in physical and sports life of the student body involves not only participation in various competitions, camping trips, mass races and other events, but also the execution of public orders related to their organization - this forms the organizational skills, initiative, sense of responsibility in the students. Skills of team management and efficient social work will be used in the future in various fields of production activity.

It should be noted that in sport competition contributes to the development of endurance, self-control and other capabilities that help to cope with the psychological intensity of training activities, and during the examination session - with the emotional overload that can also be considered from the perspective of promoting social adaptability to difficult life situations.

A social activity developed in the course of physical and sports activity becomes an essential characteristic of the individual. It always manifests itself in other spheres of public activity: membership in the student council of the university, participation in festivals, competitions, volunteer movements for parenting troubled teens and social assistance to war veterans and orphans, in student actions in the struggle for peace and against terrorism and drug addiction, etc. This helps to broaden the experience of social interaction and activity.

The presented personal abilities that characterize the social human adaptability are also necessary qualities of an expert trained at the university.

\section{Results}


The conducted survey of students of Naberezhnye Chelny Institute of Kazan (Volga region) Federal University on the impact of physical activity on the development of the individual qualities characterizing the social adaptation revealed the following.

$71 \%$ of respondents consider that the collective physical and sports activity contributes to the development of their communication skills and expand the range of social communication; 67\% - that it contributes to the unity of the training group, the establishment of friendly relations in it; $64 \%$ - that it is highly important to prepare for the professional activity.

$75 \%$ of respondents said that the process of physical improvement and participation in student competitions helps them to form such strong-willed personality traits as courage, determination, perseverance, and insistence. $12 \%$ of respondents do not agree with this statement, and the rest were undecided. The fact that physical training sessions contribute to the development of morals qualities (such as discipline, kindness, honesty, responsibility) was confirmed by $77 \%$ of the students. $8 \%$ of respondents do not share this point of view, and $15 \%$ found it difficult to give either positive or negative response to this issue.

The question of whether the physical and sports activity forms the team management skills, and whether it contributes to the development of new social roles, was positively answered by 59\% of respondents, negatively by $27 \%$, and $14 \%$ of respondents were undecided.

$62 \%$ of respondents gave positive answer to the question about the impact of sport on the development of the authority in the student team, while only $43 \%$ indicated the increase in the activity in the institute's public life (although in reality, only $40 \%$ of 239 respondents are engaged in social activities).

$70 \%$ of respondents noted the effect of sports classes on the increase in self-esteem; $74 \%$ - on selfactualization and approximation to the life goals; $32 \%$ on progress in the vertical social levels. $20-37 \%$ of respondents gave a negative answer on these issues, and many of them found it difficult to decide.

According to $56 \%$ of respondents, the motor activity influences the improvement of their mental performance, and therefore - on progress in their study. Only $27 \%$ noted the positive effect of physical training on scientific activity and creative achievements [14].

The views of young people as well as those of students of various years on all presented aspects are not significantly different statistically.

Some survey questions were about the quality of the organization of sports education in the institute. Generally, $85 \%$ of respondents give a positive evaluation of the existing system of physical education that provides training sessions, sports, hiking, physical and recreational activities, and holidays. The knowledge and skills acquired in the course of theoretical and practical training, according to $74 \%$ of respondents, contribute to the development of motivation to motor activity (they take physical training as an integral part of their life and feel the need of it). However, the analysis of the survey results showed that, despite the fact that the majority of respondents $(69 \%)$ consider it necessary to go in for sports no less than 3 times a week (i.e., at least 1-2 times), only $43 \%$ of respondents actually find time to do so, while the rest feel the university classes in physical culture to be sufficient. Unfortunately, only $24 \%$ believe that one need to do sports more - 4-5 times a week, and the experience and knowledge gained in high school will help to organize correctly the independent post-graduate physical activity.

Many students are not satisfied with a set of tools used in physical education, they ask to extend the training material with the most popular types of sports and fitness (weightlifting, body flex, shaping, pilates, hatha yoga gymnastics, etc.).

\section{Discussion}

Analysis of scientific literature, pedagogical observation and the results of the survey allow us to make a number of conclusions. The effectiveness of students' adaptation to the conditions of educational activity at the university and their social adaptability depend on many objective and subjective factors. The subjective factors include those related to the personal psychological and physiological characteristics of the students, namely, their innate abilities and personal aspirations, the development degree of social skills and performance, the level of health and physical fitness, etc. It should be noted here that physical fitness as well as a high level of health and performance having a positive impact on social adaptation of students are achieved in the process of physical training.

The objective factors of social adaptation should include the conditions of pedagogical and psychological and social environment where the process of development of the individual is implemented. These include a respectful attitude of teachers to student's personality, his/her friendly perception by the social environment, the atmosphere of confidence in the student team, etc. All these can also be implemented in the course of physical and sports activity.

\section{Conclusion}

Nowadays the necessity of improving students' sports activity on the basis of optimization of educational process, using the most effective methods and forms of classes, expansion of the applied means of physical training remain still relevant; all these points serve for the purpose of developing a person with the required properties, including the ability to social adaptation which are regarded as willingness for continuous selfeducation and a factor of professional competence.

\section{References}

1. A.V. Ponomarev, E.V. Osipchukova, Education and science: proceedings of the ural branch of the russian academy of sciences 1 (43), 42-50 (2007) 
2. A.V. Shamsutdinova, Socio-economic situation in Russia: state and prospects, 55-61 (2010)

3. Z.A. Chapkovich, V.I. Revyakina, Tomsk state university journal 420, 179-183 (2017)

4. D.A. Andreeva, Human and Society, 62-69 (1973)

5. M.S. Dmitrieva, V.I. Kaminskaia, Scientific and technological progress and staff training, 44-51 (1970)

6. A. Kolovelonis, M. Goudas, Learning and individual differences 61, 77-86 (2018)

7. I.G. Kalina, R.A. Aidarov, Socio-economic and technical systems: research, design, optimization 1(64), 80-89 (2015)

8. V.P. Ivashchenko, L.I. Khalilova, A.V. Shigabutdinov, Strategic directions of reforming the higher education system of physical culture, 251254 (2017)

9. L. Cronin, J. Allen, C. Mulvenna, Physical education and sport pedagogy 23(2), 181-196 (2017)

10. K. Richards, R. Andrew, G. McLoughlin, V. Ivy, Journal of teaching in physical education 36(4), 510520 (2017)

11. J. Marvin, International Journal of Intercultural Relations 14 (2), 251-263 (1990)

12. V.I. Goncharov, Tomsk state university journal 164 (2003)

13. C. Roure, D. Pasco, Journal of teaching in physical education 37(1), 24-34 (2018)

14. I.G. Kalina, A.I. Golubev, R.A. Aidarov, Journal of organizational culture, communications and conflict 20(3), 89-94 (2016) 